\title{
Miroslav Bistrović
}

E-mail: mbistrov@pfri.hr

Jasmin Ćelić

E-mail: cele@pfri.hr

Domagoj Komorčec

E-mail: dkomorcec@net.hr

University of Rijeka, Faculty of Maritime Studies, Studentska 2, 51000 Rijeka, Croatia

\section{Computer Vision Application for Early Stage Smoke Detection on Ships}

\begin{abstract}
Nowadays, ship's engine room is fire protected by automatic fire fighting systems, usually controlled from a place located outside the engine room. In order to activate the water mist extinguishing system automatically, at least two different fire detectors have to be activated. One of these detectors is a flame detector that is not hampered by various air flows caused by ventilation or draft and is rapidly activated and the other is smoke detector which is hampered by these flows causing its activation to be delayed. As a consequence, the automatic water mist extinguishing system is also delayed, allowing for fire expansion and its transfer to surrounding rooms. In addition to reliability of the ship's fire detection system as one of the crucial safety features for the ship, cargo, crew and passengers, using a systematic approach in this research the emphasis is placed on the application of new methods in smoke detection such as the computer image processing and analysis, in order to achieve this goal. This paper describes the research carried out on board ship using the existing marine CCTV systems in early stages of smoke detection inside ship's engine room, which could be seen as a significant contribution to accelerated suppression of unwanted consequences.
\end{abstract}

Keywords: technology, modeling, computer vision, video-based smoke detection.

\section{Introduction}

The traditional smoke detecting method requires installing the detector near possible smoke source i.e. smoke source has to be predicted. To avoid this shortcoming, a thesis is set that tries to implement smoke detection methods based on the video image processing in order to improve the performance of smoke detection and reduce 
false detections. According to statistics, the number of deaths caused by smoke is $50 \%-80 \%$ of the total number of deaths in fire, which means that smoke is the major cause of mortality. On board ship, there is always a variety of combustible waste, especially in ship's engine room, which is likely to produce large amounts of toxic gas in the combustion process and to consume large amounts of oxygen. There is a direct correlation between the amount of damage caused by fire and the intervention time required by various marine fire alarm systems. The shorter the intervention time is, the lesser the damage to the ship. In this accordance, it follows that the fire detection system main task is the timely reaction i.e. the early fire accident detection, in order to reduce possible damages.

\section{Smoke detection model based on the real time computer vision using ship's ip cameras}

Cameras for security applications are widely used especially in the field of fire detection since the fire is a significant threat affecting both the ship as well as the shore. A new idea of exploring video sequences processing in the detection and analysis of fire and smoke has emerged. One possible development direction is to use the computer vision technique which can be supplemented in the existing on-board video system and integrated within the ship's fire detection system. Conventional fire detectors are generally limited by their position in space, thus reacting only in the proximity of flame and smoke, and often cannot provide adequate on-time information about the fire incident location and fire dimension scale due to signal delay. This is why the VID system provides huge potential for successful fire or smoke detection rate in a very short period of time. Over $95 \%$ of scientific research work on the use of video technology in the early fire, smoke and flames detection is oriented towards the onshore usage. In the beginning, this technology was used to detect forest fires, afterwards it was used in large venues such as sports arenas and various large goods storages, and a logical step forward was to implement a similar technology of smoke detection in the maritime environment, specifically in ship's engine room as a fire sensitive area. 


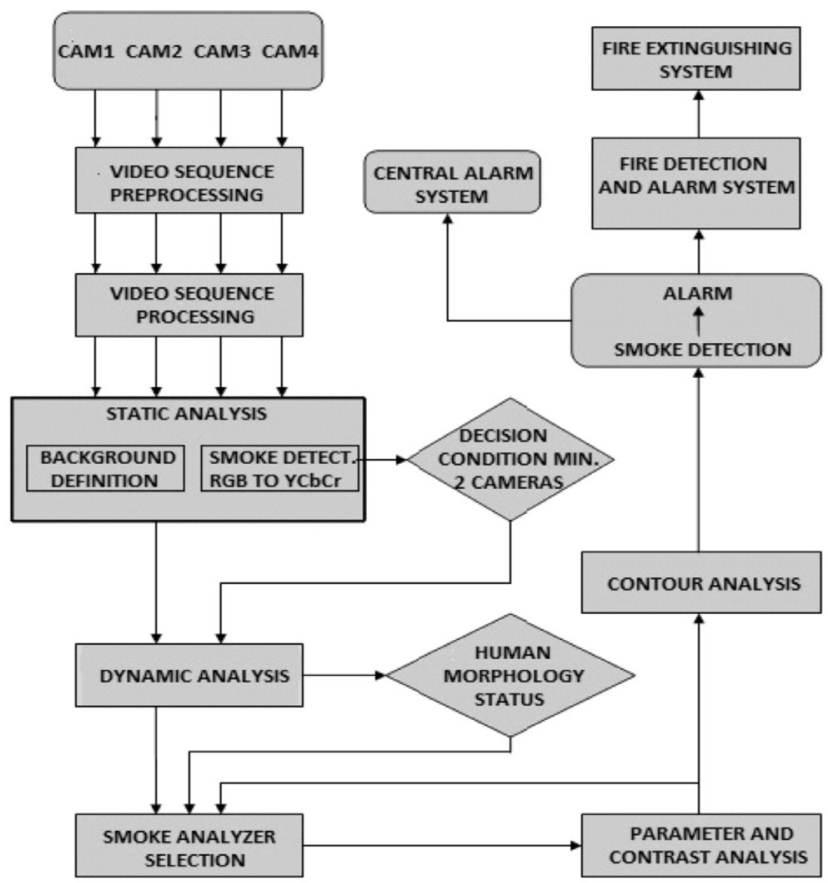

Figure 1: Smoke detection model based on the real time computer vision using ship's IP cameras

Source: Author

For the purpose of the research, a model of fire detection system was created within this project using the existing ship's CCTV system with four IP (Internet Protocol) cameras installed in ship's engine room. Visual fire detectors or IP cameras are mounted and positioned in the project-specific positions, with the task to monitor potential fire incidents that may cause smoke appearance, for example in the engine room. Cameras are recording real-time video images, analyzing them for color changes, a series of movement patterns and other parameters that indicate and have some effect only upon the behavior of smoke. The presented model is based only on the real time smoke detection and not on flame detection. The reason for omitting the flame detection in this model is in the existing flame detectors which provide satisfactory flame detection for this purpose. The proposed smoke detection model using the computer vision in real time has three crucial features: the video sequence processing with a structural analysis based on the RGB color model; dynamic analysis based on the movement of smoke under the condition that a minimum of two cameras at the same time must recognize the same smoke as a sufficient indication that the smoke does exist; analysis parameters, contours and contrast, followed by alarm and its further distribution, as seen in Figure 1. 


\section{Description of a smoke detection model based on the real time computer vision}

In most cases, fire begins with the emission of smoke and then, as it expands, flames follow. Therefore, the presence of smoke is a very important factor in discovering the source of fire. The general spectrum of smoke colors goes from white to white - bluish when the combustion temperature is low and gray to black when the combustion temperature rises to the temperature of ignition. The cameras used are the IP (Internet Protocol) CCD cameras of medium resolution with 420 TV lines (approximately 380,000 pixels). An essential element of nearly all modern cameras is a CCD sensor ( $\mathrm{CCD}=$ Charge Coupled Device). The CCD sensor is a photosensitive element consisting of a fine network of individual pixels (micro dots on the element). The observed image using IP cameras is focused through the lens onto the surface of the element, thus generating an electrical signal proportional to the intensity of the light that falls on the element. This creates an electrical form of the image that falls on the element. The number of pixels of the CCD elements falls between 250,000 and 500,000 pixels on the average.

\subsection{Video image preprocessing with DCT transformation}

For video sequences recorded by IP cameras, two of them may be used since a preprocessing is required as a prerequisite for their static analysis procedure. The task of preprocessing a video or preprocessing is to facilitate further analysis. The advantage of using the IP technology for fire detection systems against the conventional video surveillance systems is in its precision. The selected preprocessing video-based method for the proposed model was the DCT (Discrete Cosine Transform) transformation, the data compression technique used in the video image processing [1], [2], [3]. The Discrete Cosine transformation is the technique of converting the signal into basic frequency components.

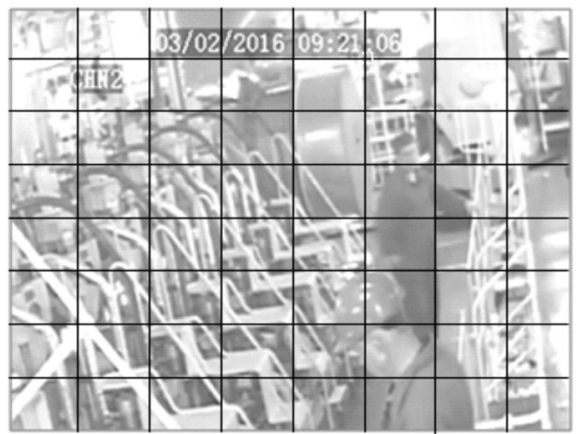

Figure 2: Video image 8 X8 coefficients conversion Source: Author 
The transformation is not performed by using whole pictures, but pictures broken up into $8 \times 8$ size blocks. The video image JPEG encoding preparation for the DCT transformation begins by converting the image from the RGB to $\mathrm{YCbCr}$ color system, where $\mathrm{Y}$ is the luminance component, and $\mathrm{Cb}$ and $\mathrm{Cr}$ are picture coloring components. After the DCT transformation process is finished, with the use of JPEG decoder inverted steps are taken to restore the original image for further analysis. The image is rendered as a two-dimensional area, which is a function of light intensity in the two-dimensional area (2D). The equation for the two-dimensional DCT transformation is given as [4]:

$$
F(u, v)=C(u) C(v) \sum_{x=0}^{N-1} \frac{\sum_{y=0}^{N-1} \frac{f(x, y) \cos \pi(2 x+1) u}{2 N} \cos \pi(2 y+1) v}{2 N}
$$

For inverted IDCT transformation the following is valid:

$$
f(u, v)=\frac{\sum_{y=0}^{N-1} \frac{\sum_{y=0}^{N-1} C(u) C(v) F(u, v) \cos \pi(2 x+1) u}{2 N} \cos \pi(2 y+1) v}{2 N}
$$

Where:

$\begin{array}{lll}F(u, v) & = & \text { DCT coefficient coordinates } \\ N i N & = & \text { horizontal and vertical components (rows and columns) } \\ C(u) i C(v) & = & \text { results set, defined by the value of } \mathbf{u} \text { and } \mathbf{v} \text { coefficients } \\ f(x, y) & = & \text { the matrix pixel value in }(\mathrm{x}, \mathrm{y}) \text { coordinates }\end{array}$

In the phase of smoke occurrence in the engine room, using the DC of each DCT block consisting of $8 \times 8$ coefficients, after several successive framework sequences of movement and color properties recordings for further analysis, it is determined whether there is any smoke, and the stored sequences are thereby being prepared for static analysis.

\subsection{Static analysis of recorded video image}

Color is a very important feature that is often presented as a RGB (Red, Green, and Blue) color model in various algorithms for smoke detection. The first rule the smoke detection algorithm is based upon is the fact that smoke is gray, which means that the intensity of the three basic RGB colors is equal. The second rule specifies that the intensity of the color gray is valued somewhere between 80 and 220, where 0 represents the color black and 255 the color white (Figure 3). The range of gray areas indicates that smoke is neither white nor so black. 


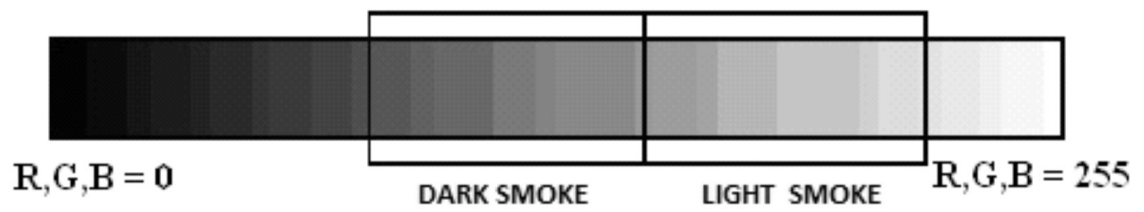

Figure 3: Colors of the RGB model which are detected as smoke Source: author

It should be mentioned as well that for each shade of gray, from both sides of the specter, the values of colors red, green and blue are equal. Based on the smoke detection modeling rules as described in the previous section, two rules can be described by equations as proposed:

Rule 1

$$
R \pm \alpha=G \pm \alpha=B \pm \alpha
$$

Rule 2

$$
80 \leq \frac{R+G+B}{3} \leq 220
$$

If both of these rules are satisfied, then the algorithm assumes that the smoke is real. But, in order to make the static analysis of smoke more effective [1], it is necessary to convert video image sequences captured by IP cameras in the MJPEG format from the RGB to YCbCr system. The HSV (hue, saturation, and value) color system has not proved to be adequate in static analysis, as can be seen from Figure 4.

RGB

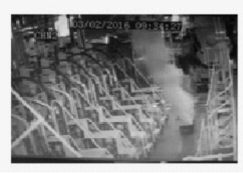

HSV

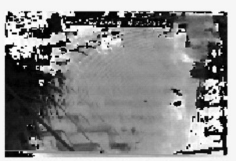

$\mathrm{YCbCr}$

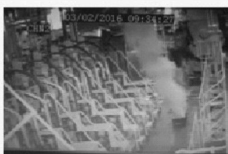

$\mathbf{L}^{*} \mathbf{a}^{*} \mathbf{b}^{*}$

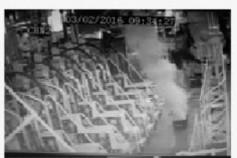

Figure 4: Different video image color models shown in MATLAB

\section{Source: author}

The further development of equations is as follows [5]:

Rule 1

$$
\left(C_{b}^{D C}(x, y)-128\right)^{2}+\left(C_{r}^{D C}(x, y)-128\right)^{2} \leq \alpha^{2}
$$

Rule 2

$$
T h_{3} \leq Y^{D C}(x, y) \leq T h_{4}
$$

Where:

$$
Y^{D C}(x, y), C_{b}^{D C}(x, y), C_{r}^{D C}(x, y)=D C
$$


$\mathrm{DC}=$ values of two chrominance and luminance channels (x, y) of the Th block applying a linear transformation between the $\mathrm{RGB}$ and $\mathrm{YCbCr}$, where from it follows that $=10, T h 3=80$ and $T h 4=220$.

If both rules are satisfied, then the (x,y) Th block considers a displayed smoke color as a real smoke and there from it follows:

$$
f_{c}=\left(Y^{D C}(x, y), C_{b}^{D C}(x, y), C_{r}^{D C}(x, y)\right)=1
$$

Otherwise it would be:

$$
f_{c}=\left(Y^{D C}(x, y), C_{b}^{D C}(x, y), C_{r}^{D C}(x, y)\right)=0
$$

Based on the video image analysis, the existence of an area affected by smoke is confirmed (by at least 2 cameras), which results in:

$$
B_{t}(x, y)=f_{m}\left(Y_{t-1}^{D C}(x, y), Y_{t}^{D C}(x, y)\right)_{c}^{f}\left(Y^{D C}(x, y) C_{b}^{D C}(x, y), C_{r}^{D C}(x, y)\right)
$$

If the binary matrix $\mathrm{B}_{\mathrm{t}}(\mathrm{x}, \mathrm{y})$ equals 1 , then the $(\mathrm{x}, \mathrm{y})$ Th block is a candidate for smoke block; otherwise, the block is discarded. To access the dynamic analysis of the video image, in addition to defining the background to the proposed model, the condition must be met of at least two cameras confirming at the same time the presence of smoke in a particular engine room area.

The background defining in the static analysis is focused on the comparison between the observed image (engine) in a video sequence and a picture that does not include any item of interest, that is the system divides the observed image of two complementary sets of pixels, where the first set comprises the objects of interest, and the other one its complementary set in the background. To define the video image background, the Gaussian color mixture model is mostly used.

\subsection{Dynamic analysis of recorded video image}

One smoke feature that the dynamic analysis is based upon is the irregularity, diffusion and direction of movement. Ship's engine room is subject to various air flows as a result of the ventilation system operation or draft. Air flow has some effect on smoke movement and its contour. Together with the problem of air flow, there is also the problem of shadows, the presence of ships crew and their movements. To make the dynamic analysis as successful as possible, it is very important to consider the background subtraction that is an area of special interest (ROI) which is compared with the background image (Figure 5). 


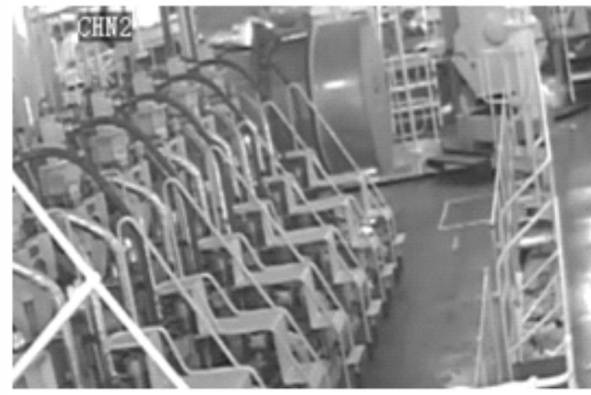

1. BACKGROUND IMAGE

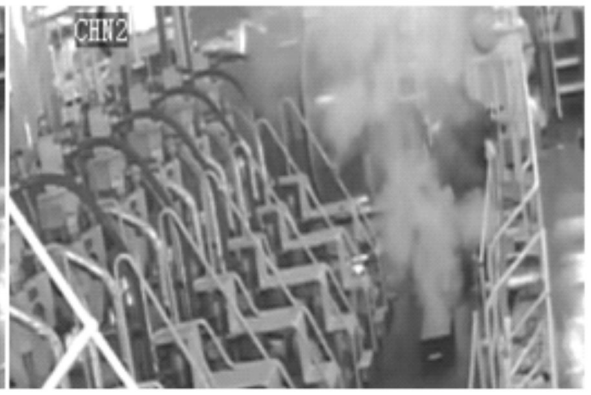

2. AREA OF INTREST AOI

Figure 5: Comparison of the background image and the area of interest AOI Source: author

The direction of smoke movement is always from the bottom upwards. In the smoke detection algorithm, the direction vector is used as a parameter. If the direction of movement is, as mentioned, from the bottom up and from the place of smoke origin towards the ceiling, the target is considered to be a real smoke. That is why the dynamic characteristics of smoke are used in order for smoke to be detected. To avoid false alarms caused by parts of a certain engine room area and objects of color similar to smoke, a threshold value is raised which is used as a reference to determine whether the smoke is real or not, and the rule reads [6]:

If the color ratio is $\geq$ than the defined threshold, then the smoke could be real. Otherwise it is not.

Diffusion, as a dynamic feature, also serves to calculate the smoke expansion rate, or the extent of the smoke, which is used as a detection indicator whether the smoke is real or not. With regard to the process of smoke diffusion, the smoke area in the picture sequence is constantly increasing. If the growth rate of smoke contours is above a certain threshold, then one can claim with a great probability that the smoke is real, and the rule reads as follows:

If the smoke expansion rate is $\geq$ than the defined threshold, then the smoke could be real. Otherwise it is not.

Due to the smoke expansion and volume increase (smoke extent), the smoke expansion rate is calculated using the equation:

$$
\Delta A_{d i}=\frac{d A}{d t}=\frac{A_{i+k}-A_{i}}{(i+k)-i}
$$


where we have:

$A i=$ smoke area as a time variable

$\mathrm{i}=$ sequence of images frame

$k=$ number of images between two selected input images

$(i+k)-i=$ frame number

Processing of video sequences intervals of the smoke covered area by the time method may be replaced by an interval of colors using the equation:

$$
\Delta A_{d i}=\frac{d P}{d t}=\frac{P_{i+k}-P_{i}}{(i+k)-i}
$$

where it is:

$P i=$ total number of smoke pixels in covered area

$i=$ sequence of images frame

$k=$ number of images between two selected input images

$(i+k)-i=$ frame number

In performing the dynamic analysis of erroneous video-smoke blocks, it is necessary to isolate such blocks including also morphological status of persons. Taking into account the expansion of smoke as a smoke characteristic, isolated blocks are considered to be erroneous blocks. The elimination of isolated blocks in the image is done using the binary matrix $\mathrm{B}_{\mathrm{t}}$.
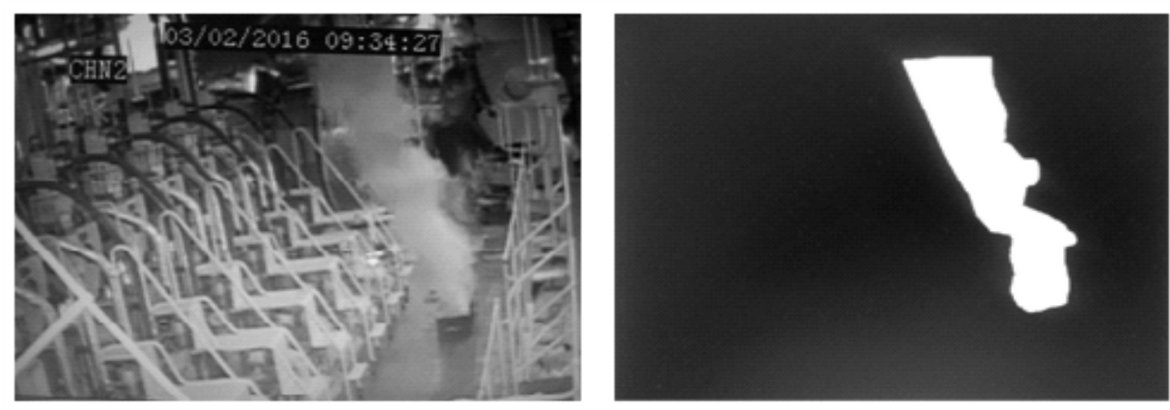

Figure 6: Isolation of detected smoke

Source: author

The proposed model of the ship's fire detection system is based on the usage of the existing CCTV system. The smoke detection model is based on the real time computer vision using the ship's IP camera for reading and analyzing video sequences in the AVI format, by means of an AVI player. The software for smoke detection can be installed either in the CCTV system or in one of the ship's computers. In order for smoke detection software or application to have an effective start, it is necessary 
to select the proper type of video smoke analyzers suitable for areas such as ship's engine room. Once the suitable video analyzer has been selected, we need to set the appropriate parameters and to access the system analysis in order to evaluate whether it is working satisfactorily or not. If the system is not working properly, the process should be repeated until it is determined that detection will be possible. The adjusted parameters are in the function of event assessment and smoke recognition.

\section{Performance evaluation of the proposed model of ships fire detection system based on computer vision}

The working principle of the visual smoke control as a new tool is based, in the very early detection of flames or smoke, on a sophisticated computer analysis and processing of video images of the area covered by CCTV IP cameras. With the latest advances in video technology using the CCTV system and the associated IP camera in the smoke and flame detection, this applied research has implemented such technology in ship's engine room. Testing the proposed smoke detection model in the real ship conditions is the basis for its future development and has brought encouraging conclusions.

To prove the effectiveness of the smoke detection model based on computer vision, experiments were carried out using conventional smoke detectors and advanced detection systems using IP cameras. The assessment of the response speed of a classical smoke detector is based on optical density, temperature rise, alarm threshold, and speed and direction of propagation. The ship's engine room ventilation system in operation reduces the optical density of smoke due to the influx of fresh air, which means that the alarm-causing optical density is significantly higher than the one affected by the operation of the ship's engine room ventilation system. For smoke detection based on computer vision, this parameter has no effect.

The proposed model of smoke detection based on the real time computer vision using the ship's IP camera is aimed at the development of video system for early warning and smoke detection integrating the existing conventional marine fire alarm system and video system into one advanced unit. The collected data and measurements are distributed in the central CCTV system unit and, with the help of the intelligent computer vision and smoke recognition, the algorithm data are automatically analyzed. The analyzed data are then used to generate some kind of warning signals or alarms to indicate that smoke has been detected. The proposed model provides the real time smoke detection information. The features and functionality of the proposed model design meet certain conditions, such as software requirements, the architecture of the proposed model, speed detection requirement, evaluation and visualization of smoke spread, economic and legal constraints, functionality, etc. Slow response time of traditional smoke detectors has led to further development of a reliable alternative for conventional detectors offering a volumetric detection system based on computer vision. 
Time, as a major factor that the proposed advanced model of smoke detection is based upon, has also the proportional impact on reducing potential fire damage. At the same time, reducing the response time greatly increases the chance for timely firefighting. The existing on-board systems of video surveillance are very affordable at low cost and can be easily upgraded to provide also video flames or smoke detection by means of the existing video surveillance.

\subsection{Monitored fire protected area and definition of initial environment conditions}

Ship's engine room is chosen as a testing area for the classical model and the proposed fire detection model. It has been chosen as a specific area where fire incidents most frequently occur. The engine room space is about 10 meters wide, 16 meters long, and about 8 meters high from the smoke simulation place to the ceiling.

Test conditions are appropriate for the actual ships' conditions in operation/navigation, that is when the complete lighting of ship's engine is on and is powered by alternating voltage of $230 \mathrm{~V}$ from the main switchboard ( 28 neon lamp $64 \mathrm{~W}$ power each, a total of $896 \mathrm{~W}$ ), an auxiliary diesel engine in operation is connected to the main switchboard, the air compressor is in operation, fuel system in operation, cooling and drive lubrication systems in operation, fire detection system in operation, the main engine ready for operation, all the doors and emergency exits closed, and the engine room ventilation in operation. Fresh air flow amounts to $19 \mathrm{~m}^{3} / \mathrm{s}$., and $68500 \mathrm{~m}^{3} / \mathrm{h}$ respectively, air density to $1,13 \mathrm{~kg}$ at the engine room temperature of $+35^{\circ} \mathrm{C}$.

\subsection{Smoke detection testing by using VID system and IP cameras}

The engine room was prepared for smoke detection by the proposed model by using the video surveillance system ELRO DVR74S, with four video channels, and four external IP cameras mounted at the designated places as shown in Figure 7. A testing video sequence was recorded by IP cameras mounted at four locations selected in a way to provide the best possible area coverage. The location of camera 1 was at the bow below the engine room ceiling, camera 2 facing downwards in the bow direction of the engine room, camera 3 facing downwards below the after part of the engine room ceiling, and camera 4 mounted at the after area of the engine room just below the ceiling also facing down to the main engine as can be seen in Figure 7. The total video sequence during the entire test was recorded for approximately 60 minutes. The test was originally recorded in compressed AVI video format. 


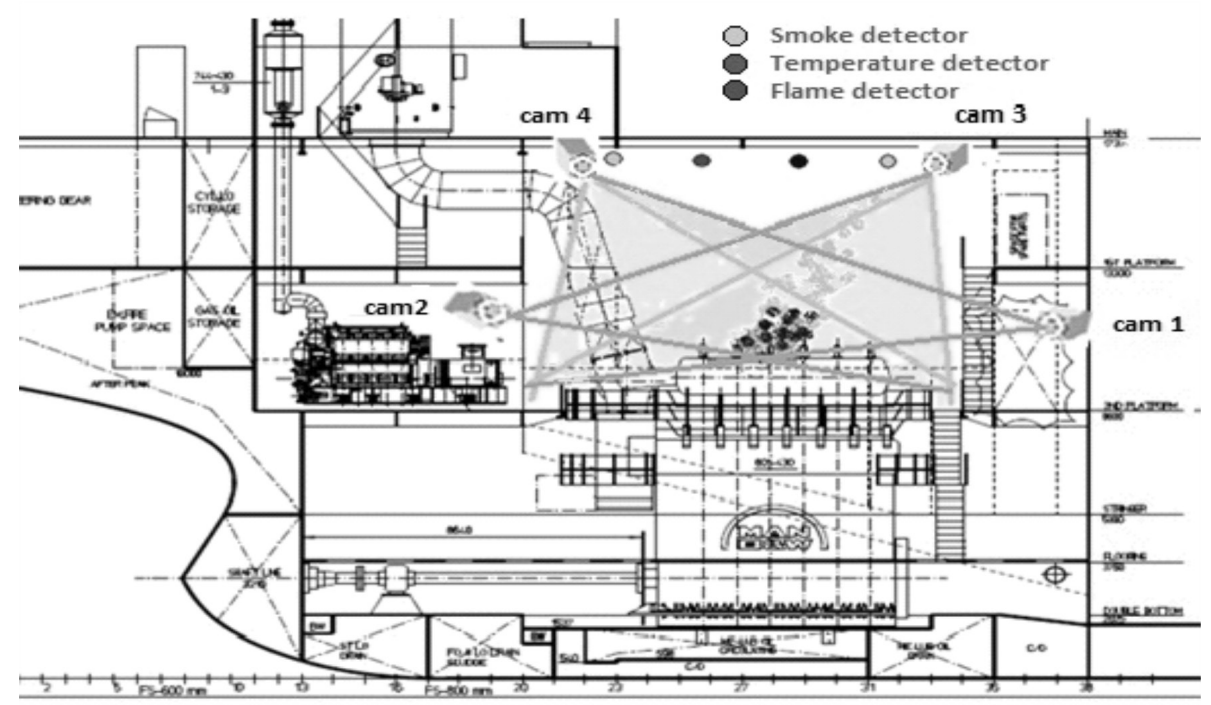

Figure 7: Positions of IP cameras prepared for a video smoke detection test Source: author

The video system ELRO DVR74S with 4 cameras (Figure 8) can simultaneously display four images on the 7-inch screen and an additional screen like the ship's computer or the CCTV screen. The built-in hard drive recorder allows for writing files on the hard disk of $500 \mathrm{~GB}$ capacity. The horizontal screen resolution is $450 \mathrm{TV}$ lines with the picture element $628 \times 586$ video in the AVI video image format. The software used during the video smoke detection test is similar to the software used for monitoring and detection of forest fires, which has already produced satisfactory results. 


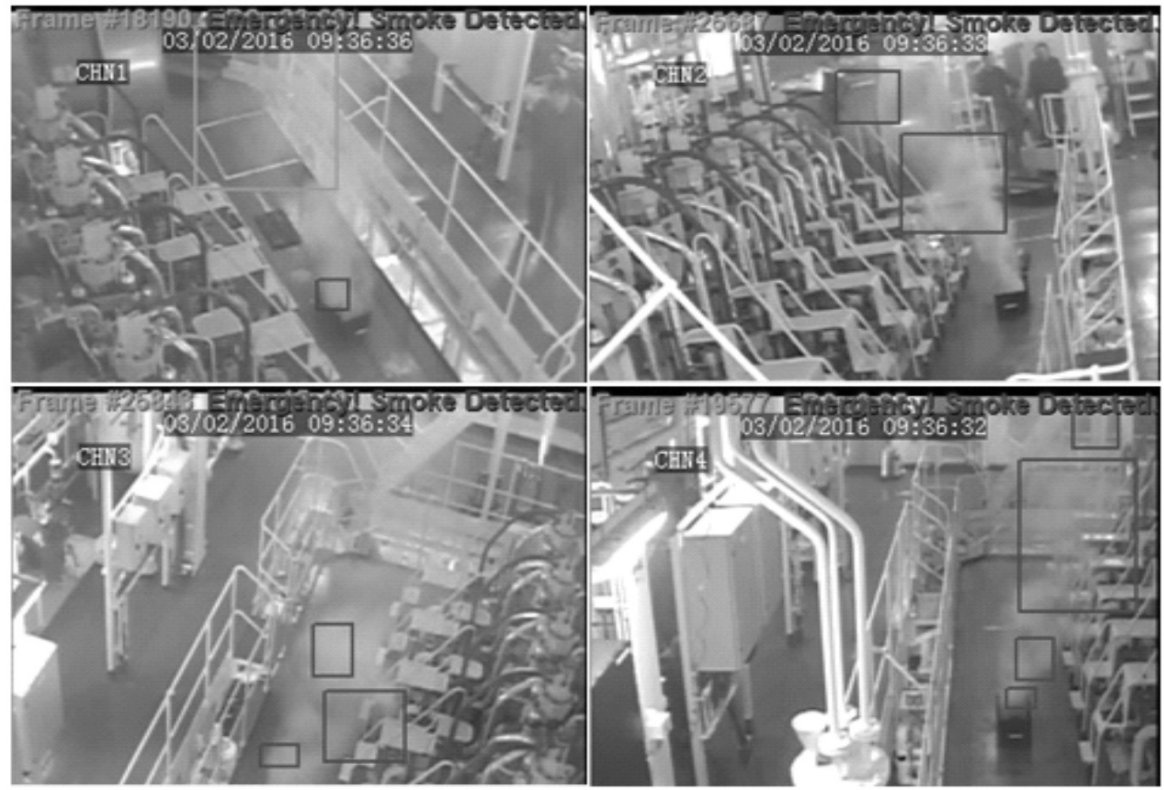

Figure 8: Video smoke detection using 4 different angle cameras in a 3 sec time gap Source: author

The testing combustible material was a mixture of the main engine heavy fuel, auxiliary engines diesel oil and tire rubber. Software settings for the video smoke detection have changed with respect to the chosen detector type. Predefined types of detectors that could be selected as video smoke detectors were a forest smoke detector (detector used for forest fire monitoring), a classical video smoke detector, and the Markov model of video smoke detector. By testing the best video smoke detector, a forest smoke detector proved to be most useful, because it provides great filtering features for the elimination of the moving background items, great vibration resistivity, light smoke adjustment with regard to the background, analysis of shadows and use of the SVM classification, sizing sample blocks, sensitivity adjustment and appropriate video sequences resolution. 
Table 1 Smoke detection alarm time during three separate tests

\begin{tabular}{|c|c|c|c|c|}
\hline & $\begin{array}{c}\text { Alarm triggering } \\
\text { time test 1 } \\
\mathrm{t} 1[\mathrm{~s}]\end{array}$ & $\begin{array}{c}\text { Alarm triggering } \\
\text { time test 2 } \\
\mathrm{t} 2[\mathrm{~s}]\end{array}$ & $\begin{array}{c}\text { Alarm triggering } \\
\text { time test 3 } \\
\mathrm{t} 3[\mathrm{~s}]\end{array}$ & $\begin{array}{c}\text { Mean alarm } \\
\text { triggering time } \\
\mathrm{t}[\mathrm{s}]\end{array}$ \\
\hline CAMERA 1 & 02.04 & 02.22 & 01.55 & 01.93 \\
\hline CAMERA 2 & 02.02 & 02.58 & 02.29 & 02.29 \\
\hline CAMERA 3 & 05.38 & 03.05 & 03.53 & 03.95 \\
\hline CAMERA 4 & 03.31 & 01.14 & 02.34 & 02.26 \\
\hline
\end{tabular}

Source: author

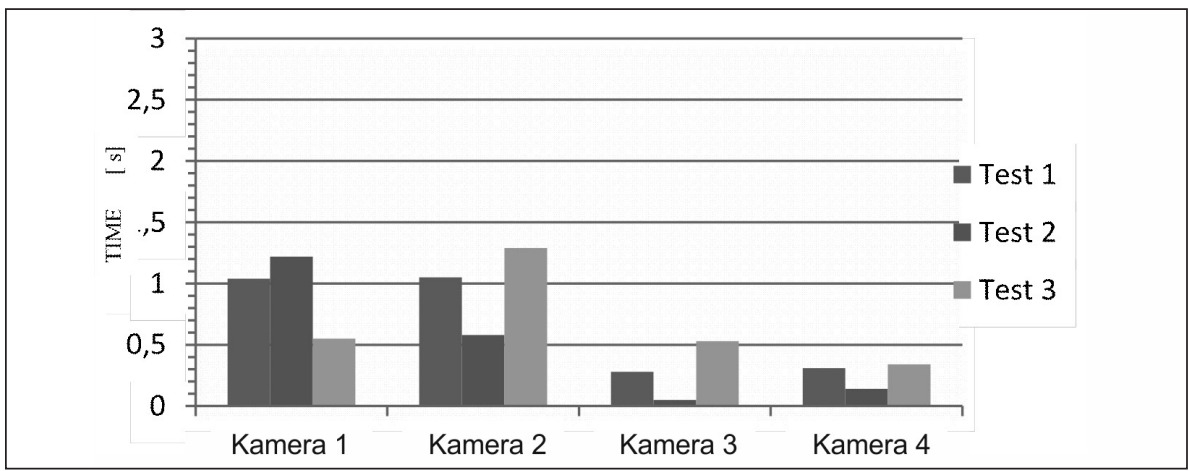

Graph 1: Smoke detection alarm time during three separate tests

Source: author

Detection speed of individual cameras with regard to the camera position is presented in Table 1. It is also visible that different camera angles will have some impact on the smoke detection speed as can be seen in Figure 8. Therefore, the precise location of cameras inside the engine room must be carefully planned.

\section{Comparative analysis of classical and camera based methods for early phase fire detection}

In order to conduct the comparative analysis of the classical method and the proposed approach in early stages of fire detection, it is necessary first to execute smoke detection testing in ship's engine room via the classical smoke detection system. Smoke detectors used in the test are type Salwico EV-P analog addressable detectors type with optical chambers, powered by nominal voltage of $24 \mathrm{VDC}$, operating current of 0.2 $\mathrm{mA}$, current alarm $5 \mathrm{~mA}$, and working range of $-25^{\circ} \mathrm{C}$ to $+70^{\circ} \mathrm{C}$. Detector location is shown in the figure below. 




Figure 10: Smoke detection with the engine room ventilation in operation Source: author-based on the Uljanik new building 722

In analyzing the operation of the proposed video smoke detection model and the conventional smoke detection systems (Table 2) according to the test results, it was shown that an automatic smoke detection system based on the video technology provides much faster response time than the conventional fire detection system. The system has shown very good performance in high ceiling areas and large areas, where the video smoke detection is not affected by the air flow or by changes in temperature and moisture, the captured image or video clips allow for finding the cause and place of fire accident occurrence, and the images make it possible for the damage to be estimated, while the system itself can be very easily incorporated into the existing ships fire detection systems.

Table 2: Alarm triggering time of optical smoke detectors with the engine room ventilation in operation

\begin{tabular}{|c|c|}
\hline $\begin{array}{c}\text { SMOKE DETECTOR } \\
\text { Inital time } \mathrm{t}=0\end{array}$ & ALARM TRIGGERING TIME tA [s] \\
\hline 07037 & $02: 56$ \\
\hline 07038 & $04: 10$ \\
\hline 07039 & $04: 50$ \\
\hline 07040 & $03: 33$ \\
\hline
\end{tabular}

Source: author 
The video technology speed to detect smoke and to trigger the alarm activation occurs on the average in time countable in seconds, while conventional detectors depend on the monitored area, the amount of space and a variety of air streams that affect the direction of the smoke.

Table 3: The alarm triggering mean time comparison between classical smoke detectors and cameras used as smoke detectors

\begin{tabular}{|c|c|c|c|c|c|c|c|c|}
\hline & $\begin{array}{c}\text { Detec- } \\
\text { tor 1 } \\
07037\end{array}$ & $\begin{array}{c}\text { Detec- } \\
\text { tor 2 } \\
07038\end{array}$ & $\begin{array}{c}\text { Detec- } \\
\text { tor 3 } \\
07039\end{array}$ & $\begin{array}{c}\text { Detec- } \\
\text { tor 4 } \\
07040\end{array}$ & $\begin{array}{c}\text { Came- } \\
\text { ra 1 }\end{array}$ & $\begin{array}{c}\text { Came- } \\
\text { ra 2 }\end{array}$ & $\begin{array}{c}\text { Came- } \\
\text { ra 3 }\end{array}$ & $\begin{array}{c}\text { Came- } \\
\text { ra 4 }\end{array}$ \\
\hline $\begin{array}{c}\text { tAB } \\
{[\mathrm{sec}]}\end{array}$ & $02: 00$ & $02: 00$ & $02: 00$ & $02: 00$ & $02: 00$ & $02: 00$ & $02: 00$ & $02: 00$ \\
\hline $\begin{array}{c}\text { tBC } \\
{[\mathrm{sec}]}\end{array}$ & $02: 56$ & $04: 10$ & $04: 50$ & $02: 33$ & $00: 40$ & $00: 20$ & $00: 53$ & $00: 33$ \\
\hline $\begin{array}{c}\mathrm{tAC} \\
{[\mathrm{sec}]}\end{array}$ & $04: 56$ & $06: 10$ & $06: 50$ & $04: 33$ & $02: 40$ & $02: 20$ & $02: 06$ & $02: 33$ \\
\hline
\end{tabular}

$\mathrm{t}_{\mathrm{AB}}=$ smoking simulation preparation time

$\mathrm{t}_{\mathrm{BC}}=$ smoke detection time

$\mathrm{t}_{\mathrm{AC}}=$ total smoke alarm triggering time

$\Delta t$ det $=$ mean smoke detection time of classical optical detectors

$\Delta t$ det $=217,25 \mathrm{sec}$

$\Delta t$ cam $=$ mean smoke detection time of video cameras

$\Delta t c a m=3,65 \mathrm{sec}$

$\Delta t v=$ smoke detection speed ratio

$$
\Delta t v=\frac{\Delta t_{d e t}}{\Delta t_{c a m}}=59,52
$$

By comparing the values listed in Table 3, it can be concluded that with the use of video cameras technology the smoke detection time is much shorter as opposed to the smoke detection using classical optical smoke detectors. Taking into account the smoke detection mean time using optical smoke detectors and the mean time using the camera, it may be concluded that the speed response of the video camera technology is 59.52 times faster than that of conventional optical smoke detectors.

The significant disadvantages of the proposed smoke detection model based on video technology are the following: the video cameras system requires minimal lighting conditions for the controlled area, the cameras must comply with the minimum technical performance requirements, the problem of excessive vibration that may affect the quality of shots, each camera requires separate parameters adjustment depending on the installation position and the environment, it is necessary to constantly clean the 
protective glass, otherwise the quality of the recording may be poor and thus affect the detection, the system still does not have the required permission for maritime use.

\section{Conclusion}

The aim of this study was to assess the effectiveness of the commercially available CCTV video systems in smoke detection on board vessels, namely in ship's engine room. The purpose of the research was focused on the ship's fire detection system effectiveness increase by using new electronic and computer technologies, specifically the video technology in the field of smoke detection, understanding the sensitivity and performance limitations that may affect smoke detection, using different cameras position and angle with the real conditions in the ship's engine room. Also, the application of new electronic and computer technologies to improve the ship's fire detection system increases the efficiency of the fire detection system, as well as the degree of availability and reliability of the ship's fire detection and protection against fire.

The reliability of the fire detection system is explained through the increased early detection probability of fire accidents (smoke) using IP cameras installed on a CCTV system with safe and successful operation of the proposed model for fault resilient operation without any system failure.

The improvement in the characteristics of the ship's fire detection system is achieved by increasing the detection speed of early stages of fire while reducing the number of false alarms detection. The comparison between the rate of smoke detection using conventional smoke detectors and fire detection using the video technology in the ship's engine room area leads to the conclusion that the smoke video detection rate provides much faster intervention time for extinguishing the fire in early stages of incident. Conventional detectors are subject to little dirt, moisture, various currents of air, which greatly enhances the number of false fire alarms, while the video cameras technology avoids such failures, provided proper maintenance.

The analysis has shown that with minimal investment in the existing fire detection systems a significant contribution is made in favor of rapid and timely fire detection information and increased security of the ship, while preserving the functionality of ship's vital equipment and systems. All these benefits of saving the ship, equipment, cargo and especially human lives bring in the overall financial and logistical gain for the ship owner. 


\section{Literature}

1. Leonardo Millan-Garcia, Gabriel Sanchez-Perez, Mariko Nakano, Karina Toscano-Medina, Hector Perez-Meanam, Luis Rojas-Cardenas., An Early Fire Detection Algorithm Using IP Cameras, National Polytechnic Institute, San Francisco Culhuacan, Mexico, May, 2012

2. Töreyin, B. U., Dedeoğlu, Y., and Çetin, A. E. 2005. Flame detection in video using hidden Markov models. In Proceedings of the IEEE International Conference on Image Processing, Genoa, Italy,11-14 September, 2005

3. B. U. Toreyin, A. E. Cetin, Real-time Fire and Smoke Detection in Video, Proceedings of IEEE International Conference on Acoustics, Speech and Signal Processing, Philadelphia, PA, USA, 18-23 March, 2005

4. [Online], http://spvp.zesoi.fer.hr/seminari/2000/kompresije/dct/dct.htm

5. Davis, B. J; Nawab, S. H.; The Relationship of Transform Coefficients for Differing Transform and/or Differing Subblock Sizes. IEEE Trans. Signal. Process. 2004. p. 1458-1461

6. Töreyin, U. B., Dedeoglu, Y., Çetin, A. E.; Flame Detection in Video Using Hidden Markov Models, Procedings of IEEE International Conference on Image Processing, 2005. p. 1230-1233

7. Celik, T., Demirel, H., Ozkaramanli, H.; Automatic Fire Detection in Video Sequences, Proceedings of European Signal Processing Conference EUSIPCO, Florence, Italy, September, 2006

8. Chen, T.; Yin, S; Huang, Y.; Ye, Y.; The Smoke Detection for Early Fire-Alarming System Based on Video Processing. Proceedings of International Conference on Intelligent Information Hiding and Multimedia Signal Processing, Pasadena, CA, USA, 18-20 December, 2006

9. Bugarić, M.; Prepoznavanje dima i vatre temeljeno na analizi digitalne slike, Faculty of Electrotechnics, Mechanical Engineering and Shipbuilding, University of Split, December, 2007

10. Bistrović, M., Tomas, V.; Application of New Techniques and Information Technology for Early Fire Detection on Ships, Our Sea, International Journal of Maritime Science \& Technology, Vol.61 No.5-6, December, 2014

11. Toreyin, B. U., Dedeoğlu, Y., Gudukbay, U., Cetin, A. E.; Wavelet Based Real-Time Smoke Detection in Video, 13th European Signal Processing Conference EUSIPCO, Antalya, 2005

12. [Online], http://www.thiecom.de/elro-dvr74s.html 


\title{
Primjena računalnog vida za detekciju rane faze nastanka dima na brodu
}

\begin{abstract}
Sažetak
Danas su brodske strojarnice zaštićene od požara s automatskim sustavima za gašenje, najčešće kontroliranim u prostoru smještenom izvan strojarnice. Da bi sustav gašenja vodenom maglom automatski startao, po pravilu, moraju se aktivirati minimalno dva različita detektora od kojih je jedan detektor plamena kojemu ne smetaju razna strujanja prouzročena ventilacijom ili propuhom te se vrlo brzo aktivira i dimni detektor kojemu ta strujanja smetaju uslijed čega njegova aktivacija kasni, a samim tim i automatsko gašenja sustavom vodene magle, uslijed čega dolazi do rasplamsavanja požara i njegovog prijenosa na okolne prostore. U ovomu radu, osim pouzdanosti brodskog vatrodojavnog sustava kao jedne od presudnih značajki za sigurnost broda, tereta, posade i putnika, sustavnim pristupom u istraživanju naglasak je stavljen na primjenu novih metoda otkrivanja dima kao što je računalna obrada i analiza slike u svrhu detektiranja dima. Rad opisuje provedena istraživanja na brodu primjenom već postojećih brodskih CCTV sustava u ranom otkrivanju dima u strojarnici, što bi bio doprinos bržem suzbijanju neželjenih posljedica.
\end{abstract}

Ključne riječi: tehnologija, modeliranje, računalni vid, videodetekcija dima. 
